Article

\title{
Blockchain-Enabled Trade Finance Innovation: A Potential Paradigm Shift on Using Letter of Credit
}

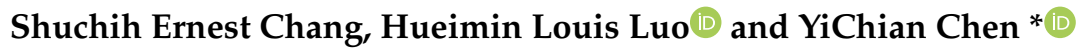 \\ Graduate Institute of Technology Management, National Chung Hsing University, Taichung 40227, Taiwan; \\ eschang@dragon.nchu.edu.tw (S.E.C.); louisluo7755@gmail.com (H.L.L.) \\ * Correspondence: cycx1000@gmail.com
}

Received: 29 November 2019; Accepted: 23 December 2019; Published: 25 December 2019

\begin{abstract}
This paper explores a potential paradigm shift in trade finance utilizing blockchain technology. Traditionally, the centralized operating model has governed trade finance and the manner in which traders handle business processes. However, such heavy reliance on centralized authorities has made for poor performance, the lack of flexibility and transparency, and vulnerability to malicious alteration. The blockchain, as a distributed ledger technology (DLT), has attracted growing attention and has the potential to disrupt legacy finance procedures such as payment by letter of credit $(\mathrm{L} / \mathrm{C})$. International trade players may benefit from the technological reengineering of financial processes through the implementation of blockchain- and smart contract-based platforms. From the conceptual perspective of a paradigm shift, this study analyzes the feasibility of blockchain innovation in trade finance through modern blockchain-based L/C initiatives. Moreover, this study also explores blockchain applications in terms of logistics tracking and how it integrates with trade finance procedures. This study contributes to the understanding of a blockchain paradigm shift with a multi-case study. The results may illuminate the potential future application of blockchain finance and provide researchers with an illustrative example of other finance-related capabilities. Studies of trade-related topics such as customs clearances, insurance, and logistics applications need to be addressed in the future to create a comprehensively trustless environment and facilitate the automation of trade.
\end{abstract}

Keywords: blockchain; trade finance; letter of credit (L/C); smart contract; distributed ledger technology (DLT); paradigm shift

\section{Introduction}

The advent of blockchain technology has drawn increasing attention of academia and practitioners alike. Recent topics focus on discussions of how the blockchain may help business operations and the role it plays in various contextual sectors [1]. One such topic of interest is trade finance, particularly international trade involving different types of trading parties. Trade finance relies heavily on paper-based business operations involving information transmission, asset transfers, goods handovers, and payment processes. Traditionally, business parties build trust with a centralized operating mechanism, such as payment by letter of credit (L/C) [2]. However, low efficiency and vulnerabilities to malicious alterations have hindered overall performance. Decentralization of operating business networks may help to improve issues such as transparency, real-time tracking, and trustless transactions among players. Researchers have stressed the importance of ensuring sustainable business environments by means of sustainable finance, corporate social responsibility, and performance [3]. Efforts on building trust among trade stakeholders, thus, eliminating friction because of information transmission/confirmation through emerging technologies, are of the utmost significance in terms of achieving environmental sustainability in the corporate milieu. 
The increase in technology-based risks, such as cyber-attacks and malicious hacking, has jeopardized business operations and finance practices [4], prompting the development of alternative solutions for establishing more secure and sustainable business finance by developing new and innovative working paradigms. The blockchain, serving as a shared ledger (database), may facilitate trade finance by means of its distributed network, which maintains transparent records of critical transactions among trading stakeholders [5]. The blockchain could potentially enhance transaction transparency and supply chain traceability [6-8]. In addition, its affiliated technology, the smart contract, may be deployed in the blockchain environment to execute event-based contract terms or agreements [9]. This paper aims at providing evidence of the potential for the blockchain to improve traditional L/C payments and traceability, by analyzing extant literature and contemporary initiatives. Using the concept of paradigm shift, this multi-case comparison study attempts to answer the research question: How may the blockchain help trade finance from the perspective of $\mathrm{L} / \mathrm{C}$ payment projects, such that it contributes to a better understanding of blockchain innovation in trade finance besides illuminating the impact of such distributed network paradigms?

This study contributes to the literature and practice in three ways. First, we investigate emerging trade cases that allowed an understanding of the potential of blockchain technology in trade finance. As blockchain and smart contracts are considered promising with unique characteristics, such as immutability, accountability, and automatic attributes, they are particularly valuable in reforming business processes in complex trade finance scenario. Second, this paper illustrates how blockchain and related smart contract technology may facilitate business processes. This paper explores blockchain's roles in streamlining supply chain activities and the value it might provide in terms of process re-design. Third, we provide an overview of cases that examined blockchain-based applications in trading activities. From these pilot initiatives, the feasibility and potential value in pursuing a sustainable supply chain can be further elucidated. This study will help researchers and practitioners gain insight into blockchain applications in trade-related financial processes.

This paper is structured as follows. Section 2 reviews related work. Section 3 describes research method and introduces cases. Section 4 elaborates research findings and builds link to paradigm shift. Section 5 presents a comparative discussion before making concluding remarks in Section 6.

\section{Background}

\subsection{Trade Finance with Letters of Credit}

Trade finance has played a crucial role in international trade. According to diverse levels of risk, traders may choose different payment terms to satisfy various strategic concerns. Generally, L/C (also known as documentary credit) stands for a documentary proof of trust and is the payment modality preferred by exporters because of its lower risk level. Payment is made once terms or conditions are met. Traditionally, $\mathrm{L} / \mathrm{C}$ involves various types of business activities and suffers from issues such as tedious document processing, higher issuance cost, and forgery/counterfeiting.

Figure 1 shows a typical illustration of an L/C process in an international trade transaction. Normally, the typical trade participants are sellers (exporters), buyers (importers), shippers (logistics carriers), and the banks that manage credit operations. Trade activities consist of three major flows: document, cash, and logistics flows. In general, international trade starts with the establishment of a sale contract between a seller and a buyer. To reduce potential risks between trading parties, certain kinds of payment methods, such as payment by delivery, telegraphic transfer, open account, and $\mathrm{L} / \mathrm{C}$, are introduced and adopted in various contexts to mitigate potential trading uncertainties. Among these, the L/C method is considered to be a highly secure payment modality with respect to trade financing. Banks in the countries of the seller and buyer function as dominant intermediaries facilitating the transaction, namely, the exchange of cash and physical goods. The buyer asks their bank to issue an $\mathrm{L} / \mathrm{C}$ to the seller's bank, which advises the seller to check the received $\mathrm{L} / \mathrm{C}$ for the exchange of goods. The seller arranges shipment to the buyer, while the shipper provides shipping documents, 
such as a bill of lading $(\mathrm{B} / \mathrm{L})$, to the seller. The $\mathrm{B} / \mathrm{L}$ is considered to be a physical warranty to claim ownership of the goods and is, in turn, forwarded to the seller's bank and finally sent to the buyer's bank, after which payment is made to the seller's bank. Finally, the buyer pays their bank in exchange for the $\mathrm{B} / \mathrm{L}$, which they present to the shipper to claim the goods when delivered. The traditional $\mathrm{L} / \mathrm{C}$, as a kind of documentary credit, is comparatively secure to other payment methods, but processing it is complex and time-consuming. Multiple participants doing cross-border business with unfamiliar counterparties may cause communication and coordination difficulties that result in high costs and poor user experiences [10]. The difficulty of document and information transmission has jeopardized the widespread adoption of $\mathrm{L} / \mathrm{C}[11,12]$.

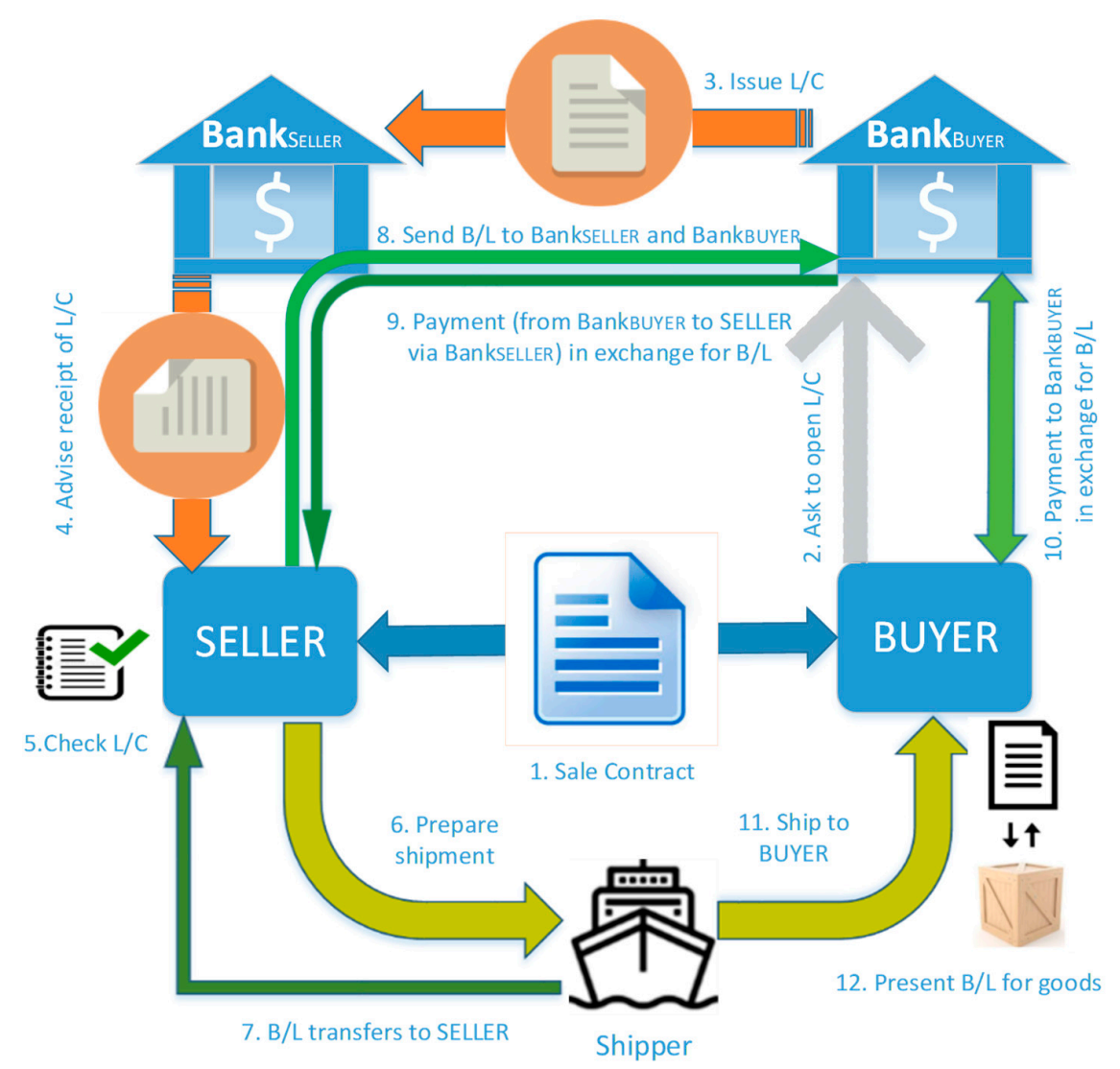

Figure 1. A typical letter of credit $(\mathrm{L} / \mathrm{C})$ payment process.

\subsection{The Blockchain and Smart Contracts}

The blockchain functions as a distributed database by creating time-stamped blocks via cryptography. It is the underpinning technology of Bitcoin and enables the bookkeeping of digital transactions on blocks [13]. With unique consensus mechanisms, such as proof of work (POW), the blockchain may provide better transparency, immutability, and auditability because of its intrinsic distributed network and consensus mechanism qualities [14]. The blockchain permanently maintains transaction records in blocks, and thus, it enhances the transparency and security level of transactions. With such features, the blockchain has drawn attention of researchers who argue that the innovative application of the blockchain may transform supply chain management $[8,15]$ as well as the insurance and finance industries [16-18]. Guo and Liang [19] argued that the blockchain may revolutionize traditional banking operations, along with payment systems, by formulating a multicenter and less-intermediated paradigm while blockchain potential in logistics may solve logistics-related issues [20]. Our study examines complex trade finance processes and attempts to reengineer the $\mathrm{L} / \mathrm{C}$ process as an example of a potential revolutionary, paradigm-shifting blockchain application. 
The smart contract refers to a series of digital agreements, including terms and conditions promised by contract participants [9]. With its programmable protocol, the smart contract allows the execution and automation of contract terms. Smart contracts may be deployed on the blockchain platform and applied to activate code execution through event triggers for various applications in a business context [21] in that business activities among global trade participants may be considered to be a suitable use of the smart contract. When compared with the heavy use of paper contracts and trade documents in global trade, a smart contract deployed on the blockchain provides a seamless solution that may prevent tampering and counterfeiting. Traditional $\mathrm{L} / \mathrm{C}$ processes rely heavily on centralized business operations, whereas the integration of the smart contract and the blockchain into trade processes mitigates issues such as counterfeiting and malicious alteration [10].

The blockchain, combined with the deployment of smart contracts, provides a more secure, transparent, auditable, and automatic transactional environment for trade stakeholders. The underlying event-driven mechanism facilitates smart contract interactions. State changes in trading activities and updated logistics/payment statuses are considered to be one-of-a-kind events on the blockchain. Smart contracts may be programmed according to the terms of contractual agreements, and payments may be triggered by predetermined events. Blockchain-based smart contract applications have the potential to transform traditional business operations by enabling the deployment of various customized applications across different industries.

\subsection{The Concept of Paradigm Shift}

The term "paradigm shift," coined by Thomas Kuhn in 1962, refers to a radical change or a revolution in a scientific discipline in terms of personal beliefs, basic concepts, thought patterns, and technological or social system practices [22,23]. From the traditional practice of intermediary finance to a more transparent and automatic payment process, the blockchain network may alleviate the need for transaction verification that is currently provided by centralized authorities in brick-and-mortar banking operations. A paradigm shift from a centralized process (the current banking practice) to a distributed collaborative network (the blockchain) may enable the facilitation of process automation and the practice of value transfer via a centralized, transparent ecosystem.

Trade finance has long been subjected to a poor level of efficiency, heavy manual processing, and lengthy delivery of trade-related documents, such as the presentation of $\mathrm{B} / \mathrm{L}$ in exchange for the ownership of goods. Handovers via shipping increase uncertainty and decrease real-time traceability. Traditional trade finance via $\mathrm{L} / \mathrm{C}$ relies heavily on the trust mechanism accumulated by intermediaries (e.g., banks). A blockchain innovation may be to reengineer business processes and offer a better value proposition in terms of validity, auditability, and disintermediation [24] in trade processes.

In modern business processes, a blockchain-enabled L/C might provide better document digitization because of its immutable functionality. When compared with traditional paper-intensive processing, the blockchain may have the potential to present an innovative value from the perspective of cost and time reduction in financial processes. Smart contracts deployed on the blockchain could automatically execute business logic transactions and reduce the involvement of human intervention in order to avoid unnecessary error and intentional, malicious manipulation. The consensus mechanism underpinning blockchain technology may enable distributed networks to achieve less intermediation and improve how trade counterparties interact with each other. In this sense, more streamlined, secure, and transparent financial transactions could enhance the overall efficiency of trade.

\section{Materials and Methods}

In the present study, recent projects were explored to demonstrate that blockchain $\mathrm{L} / \mathrm{Cs}$ are a potential tool for improving incumbent trade finance processes. Our hypothesis stems from a multiple-case study, which is believed to provide better insights than a single-case study [25-27]. Prior researchers have devoted similar efforts in exploring the role of the blockchain in achieving critical supply chain objectives such as cost, speed, dependability, sustainability, etc. [6]. By adopting 
multi-case studies, nascent pilot materials deriving from webpages, news, and company reports are accessed to provide general overviews. Similar efforts could be referenced in blockchain applications in the marine industry [28]. However, little research effort has specifically focused on an analysis of the use of $\mathrm{L} / \mathrm{C}$ in assisting trade finance, particularly from the perspective of promoting a paradigm shift. This article also seeks to provide proof for a potential shift in trade finance paradigms by using empirical evidence drawn from multiple cases. In doing so, we aggregated different scenarios of the blockchain application of trade-related procedures that deal with L/Cs and B/Ls.

Thomas [29] considered the case study to be a systematic analysis of a specific target from a wide perspective in order to better understand it, whereas the case study may not only be limited to the analysis itself but also enable better comprehension through the process of exploration. Case study results may elucidate the understanding of competitive strategies and operational business schemes, the development of theories, and the evaluation of system performance [30]. Therefore, the objective of a case study may be to analyze people, businesses, events, systems, countries, or any other specific unit, with an extensive overview or detailed investigation. Cases of interest may be studied singly or jointly for the pursuit of generalization. Therefore, researchers categorize case studies into two major types: single and multiple. For example, Creswell [31] defined and classified the method of the case study as an exploration of "contemporary bounded system (a case) or multiple bounded systems (cases) over time, through detailed, in-depth data collection involving multiple sources of information ... and reports a case description and case themes."

While case studies, from a qualitative perspective, help with the comprehension of selected targets, in making the choice of using a single- or multiple-case study, one needs to consider research objectives, contexts, expenses, and representativeness [27,32]. Multi-case studies enable researchers to discuss data within and across different situations [27]. In this sense, a multiple-case study allows a comparative understanding across the evolution of specific phenomena even though it might be time-consuming, expensive, or more complex to do so during its implementation. By comparing various cases, researchers are more likely to extract common characteristics, give explanations, and develop more reliable theories from the underlying evidence. This study utilizes a multiple-case study methodology along with comparative analysis to acquire insight into the similarities and differences among blockchain-based L/C projects. The additional benefit of choosing the multiple-case study methodology lies in its capability to explain the potential paradigm shift in $\mathrm{L} / \mathrm{C}$ processes. The proven evidence resulting from the selected cases may also provide the literature with extended scope and identify the importance of blockchain-related trade finance solutions.

\subsection{General Principles for Case Selection}

To better capture diversity and representativeness, Seawright and Gerring [33] suggested that the selection of cases should cover the general population and take extreme cases along with diverse cases into consideration to further increase the scope of the cases' analyses. For extreme case consideration, we focused on representative pioneers of pilot projects, that is, early adopters of blockchain-enabled $\mathrm{L} / \mathrm{C}$. Moreover, to extend the diversity of cases among existing blockchain finance projects, we also included highly related cases dealing with B/Ls. The researchers used various sources, including news archives, consulting reports, academic articles, and company websites, all of which contributed to the selection and description of target cases. For all cases selected, sufficient information from secondary resources was required for the performance of the subsequent case analysis.

Table 1 reports existing pain points among global trade procedures and business processes. In addition, it also presents the potential advantages of using blockchain-based solutions and indicates where such technology may penetrate for resolving related issues. Based on Table 1, this study selected modern pioneers as observational targets and investigated how these capabilities may have helped trade finance. Emerging trial projects using blockchain platforms, such as Ethereum and Hyperledger, have been announced and have drawn increasing attention of enterprises [34-37]. We selected cases exhibiting at least two or more of the reported issues listed in Table 1 . Such criteria ensured the quality 
and functionality of the selected cases. This study also used archive-based data and related secondary resources, such as trial project websites, consulting reports, news reports, and review comments. For instance, the Maersk case was selected because of its consideration of accessible information richness, representativeness in global trade roles, and capability to affect followers [38]. In addition, we traced the development of the selected project not only by visiting the related company's websites but also by gathering information from relevant reports by the press or other parties. This was done to avoid information bias and to enhance the objectivity of case selection [39].

Table 1. Global trade pain points and potentials via using blockchain L/C.

\begin{tabular}{|c|c|c|}
\hline Issues & Global Trade Pain points & Potentials utilizing blockchain $\mathrm{L} / \mathrm{C}$ \\
\hline Trust Mechanism & $\begin{array}{l}\text { Heavily relying on an authorized central party } \\
\text { (e.g., banks) as intermediary to cope with } \\
\text { trade finance. }\end{array}$ & $\begin{array}{l}\text { Use of immutable, consensus-based, and } \\
\text { distributed ledger network to build up trustful } \\
\text { trade environment }\end{array}$ \\
\hline $\begin{array}{l}\text { Fraud and } \\
\text { authenticity }\end{array}$ & $\begin{array}{l}\text { Malicious attempts which may cause fraud, } \\
\text { alterations, later trade disputes; } \\
\text { Authorities involved in building up trust among } \\
\text { trade parties. }\end{array}$ & $\begin{array}{c}\text { Keeping contract terms on blocks and } \\
\text { permanently recording alterations of contract } \\
\text { terms on a chain; } \\
\text { Mitigating the tampering issue. }\end{array}$ \\
\hline Document type & $\begin{array}{l}\text { Paper-based and manual processing; } \\
\text { Lengthy delivery. }\end{array}$ & $\begin{array}{c}\text { Digitized documents deployed on a secured and } \\
\text { distributed shared ledger. }\end{array}$ \\
\hline Transactions & $\begin{array}{c}\text { Risk-sensitive; } \\
\text { Relying on authorized third parties. }\end{array}$ & $\begin{array}{l}\text { Risk mitigation. Trust ensured through the use of } \\
\text { consensus mechanisms. }\end{array}$ \\
\hline $\begin{array}{l}\text { Bill(s) of lading } \\
\text { (B/Ls) }\end{array}$ & $\begin{array}{l}\text { Intensive paperwork for presentation. } \\
\text { Lengthy delivery across borders; } \\
\text { Complex ownership transfer across handovers. }\end{array}$ & $\begin{array}{c}\text { Digitized operation; } \\
\text { Reduced time of transfer and delivery, } \\
\text { Blockchain-based identification without } \\
\text { presentation of } \mathrm{B} / \mathrm{Ls} \text {. }\end{array}$ \\
\hline $\begin{array}{l}\text { Information } \\
\text { transmission }\end{array}$ & $\begin{array}{l}\text { Manual processing which takes the expense of } \\
\text { time and cost; } \\
\text { Centralized data manipulations which may suffer } \\
\text { from cyber-attacks or system malfunction. }\end{array}$ & $\begin{array}{l}\text { Event-driven mechanism with smart contract } \\
\text { settings. Consensus mechanism with } \\
\text { tamper-proof features. Less security and privacy } \\
\text { concerns on consortium chain }\end{array}$ \\
\hline Traceability & $\begin{array}{l}\text { Complex trade processes due to } \\
\text { multiple participants; } \\
\text { Uncertainties caused by handovers in tracking } \\
\text { asset identities, ownership, and shipment status. }\end{array}$ & $\begin{array}{l}\text { A member database which can be searched for an } \\
\text { examination of credit ratings, thus resulting in } \\
\text { better user experience. }\end{array}$ \\
\hline
\end{tabular}

\subsection{Selected Cases}

\subsubsection{Case A: Ornua's L/C (Wave)}

Barclays announced its cooperation with an innovative start-up, Wave, a decentralized blockchain hybrid crypto asset exchange platform, and initiated the supposed first global trade with its blockchain-based L/C project on 6 September 2016 [40]. This illustrative case shows how the blockchain can allow the restoration of trust in trade. Target goods, namely, cheese and butter, were transacted between Irish agricultural food cooperatives Ornua (formerly the Irish Dairy Board) and the Seychelles Trading Company [41]. Ornua has suffered from expensive export coverage across countries, particularly for the time-intensive, complex, and lengthy processing of $\mathrm{L} / \mathrm{C}$ issuance and approval. Barclays reported a great reduction in trade finance processing time (particularly, it was completed within four hours). The operation of a blockchain-based L/C system averts paper-heavy transmission, and traders can, therefore, benefit from the adoption of the blockchain. Overall performance was enhanced with the employment of a more streamlined cross-border transaction.

The blockchain platform, Wave, utilizes the blockchain as a shared ledger to store trading documents (i.e., B/Ls). Participating parties, including banks and trading counterparties, are able to access on-chain data to track the flow of information and goods. In addition, Wave uses smart contracts deployed on the blockchain to log the transfer of ownership. Smart contracts, in this sense, may facilitate payment processes upon preset terms, such as upon the arrival of goods to port. The presentation of a B/L triggers the execution of an ownership transfer. Traditional financial procedures related to document collection, approval, and presentation are incorporated with the integration of the blockchain 
and smart contracts. The underlying working scheme proves the feasibility of a distributed ledger system in such a trade process.

\subsubsection{Case B: Mizuho and Marubeni (Hyperledger)}

On 6 July 2017, by using blockchain technology the Japanese company Marubeni and Sompo (an insurance company) demonstrated the manner in which the application of DLT replaces the use of L/Cs and other trade-related documents. The trade deal was conducted using IBM's Hyperledger Fabric platform, which reduced the transaction duration from weeks to approximately two hours. Figure 2 illustrates the workflow of this L/C transaction.

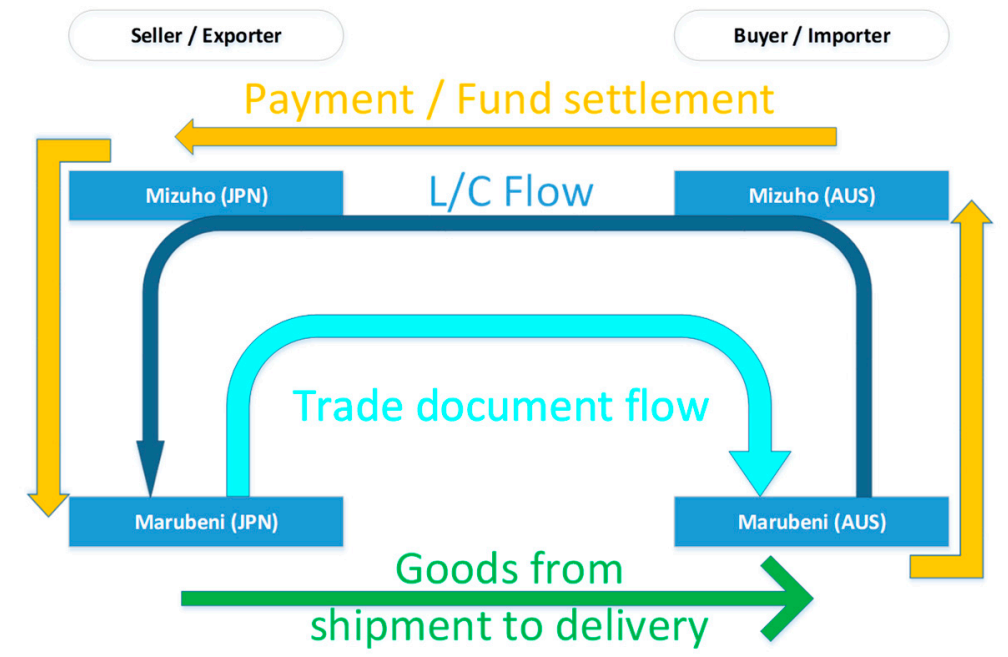

Figure 2. A conceptual overview of the L/C process, as conducted by Marubeni Corporation.

To a great extent, a hyperledger platform enables a great reduction in the use of traditional trading and shipping documentation, via the use of DLT. From sales contract establishment, request for L/C issuance, and handover of documents ( $\mathrm{L} / \mathrm{C}$ and $\mathrm{B} / \mathrm{L}$ ), to final payment and fund settlement, the banks of the exporter and the importer completed a trial transaction over the blockchain network. However, to achieve a critical mass of blockchain adoption in the trade industry, technical issues on common protocols and collaborative willingness from users will be influential in its future development [42].

The blockchain and DLT may enable speedy, risk-free, and fraud-proof transactions between unfamiliar parties. Paperless documentation flows, along with auditable monitoring schemes, have attracted many followers. The high cost of administrative procedures and the high volume of paperwork is greatly reduced, while issues such as the lack of wider adoption among trading parties and information standardization at the international level are yet to be resolved [43]. With an event-driven mechanism (EventBridge in Hyperledger), multiple participants receive message notifications from preregistered smart contracts. The functionality of the blockchain serves as a business-to-business (B2B) messaging layer while business interactions are designed accordingly to react to triggered events, for example, the arrival or delivery of goods triggers a payment request [44].

\subsubsection{Case C: Maersk and IBM (Hyperledger Fabric)}

In September 2016, Maersk, a leading container shipping corporation, initiated a tracking project with IBM for flower shipments from Kenya to the Netherlands. Participating parties included shippers, freight forwarders, customs authorities, and traders. This solution was targeted to improve logistics monitoring and shipment traceability. Likewise, the critical issue to be resolved was the significant volume of paperwork for related containers. Maersk and IBM collaboratively worked on the digitization of documentation and formulated a visible shipment framework for each shipping participant. Document-related signatures were digitized with cryptography techniques to prevent 
malicious counterfeiting. Hyperledger Fabric functioned as the common shared ledger, which was collaboratively maintained by the participating parties. With regard to this, an auditable, immutable ledger was formulated and could be used to reduce physical processes and paperwork in such cross-border trades [45].

Numerous communications on settling administrative procedures have often caused disputes and latency of shipments. A high incidence of fraud and the onerous costs of managing paper documentation may be averted, or greatly reduced, by the adoption of blockchain-based shared ledgers. Maersk reported that an estimated one-fifth of the cost was saved in terms of the actual physical transportation of goods. This project provided shipping visibility on the basis of participants' levels of permission [46]. Customs clearance documents and B/Ls can be viewed and tracked to enhance overall transparency and process information reliably. In addition, Maersk also devoted efforts to the simplification of the $\mathrm{L} / \mathrm{C}$, which increased willingness to adopt blockchain ecosystem participation [47]. Future solutions that combine the blockchain and the Internet of Things (IoTs) are the next focus, and research efforts to improve the performance of blockchain trading systems are encouraged.

\subsubsection{Case D: HSBC Trade Transaction with Cargill via Voltron (Corda Blockchain)}

In 2018, HSBC announced its first blockchain-based trade for the U.S.-based food and agricultural group, Cargill, via blockchain L/C. The case adopted a consortium chain to provide soybean shipment solutions and facilitated transactions between HSBC and the R3 counterparty, the Dutch bank ING. From Argentina to Malaysia, this project utilized an R3 Corda blockchain to realize food traceability [48]. This pilot project inherently took advantage of blockchain features to simplify manual processing and paperwork when dealing with L/Cs. Traditional lengthy exchanges of export documentation were largely reduced with an associated reduction in costs. Figure 3 shows the process flow (in terms of a sequence diagram, SD) along the trade finance life cycle. ING and HSBC are acting as intermediary banks to bridge the transaction between Tricon Energy (buyer) and Reliance Industries (seller). Both banks are Voltron L/C consortia members using R3's Corda technology.

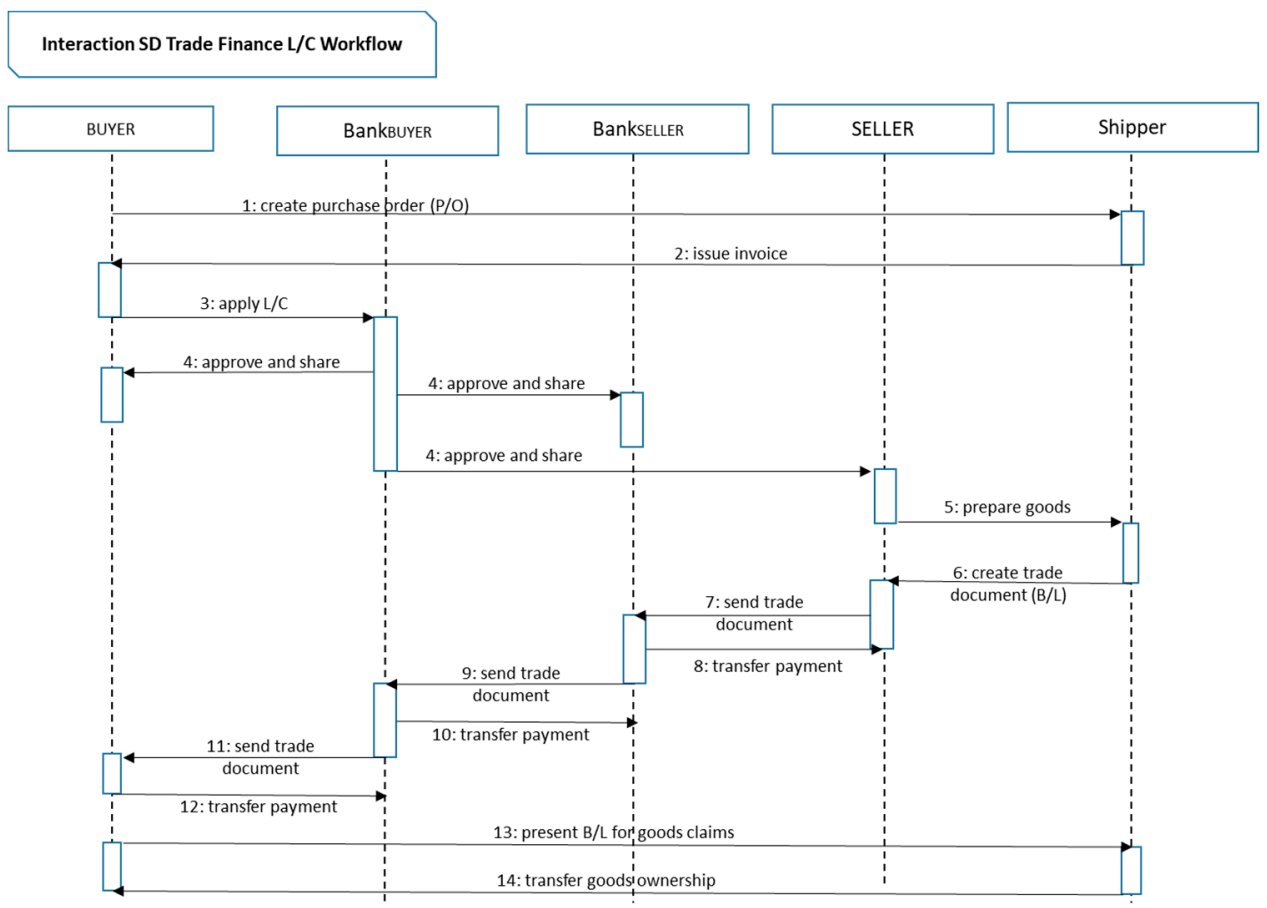

Figure 3. Flows between nodes along the trade finance life cycle on Corda.

Corda is an open-source blockchain platform for business scenarios. Corda differs slightly from a traditional blockchain platform because of its capability to minimize information leakage (by only 
dealing with crucial transactional data) and its compatibility with legacy infrastructure (which achieves better interoperability). It is designed for permissioned groups of participants and enables easy management of legal contracts and shared data between trusted parties. Corda averts unnecessary data sharing in the consortium contextual network and allows access control by dominant parties (usually referring to banks).

\subsubsection{Case E: BBVA B/L (Ethereum Blockchain, Wave)}

In 2018, Banco Bilbao Vizcaya Argentaria (BBVA), a Spanish bank, used blockchain technology as a substitute for traditional trade documents (such as B/Ls) to reduce transaction time from 10 days to less than three hours [49]. This project consisted of the exportation of frozen tuna from Mexico and the L/C payment issued by BBVA. The blockchain solution provider, Wave, utilized digitized documentation and electronic signatures to replace traditional paper-based documents. A special feature was the electronic presentation of documents during international transactions (Figure 4).

BBVA accelerates electronic document presentation and processing in international transaction with Wave technology

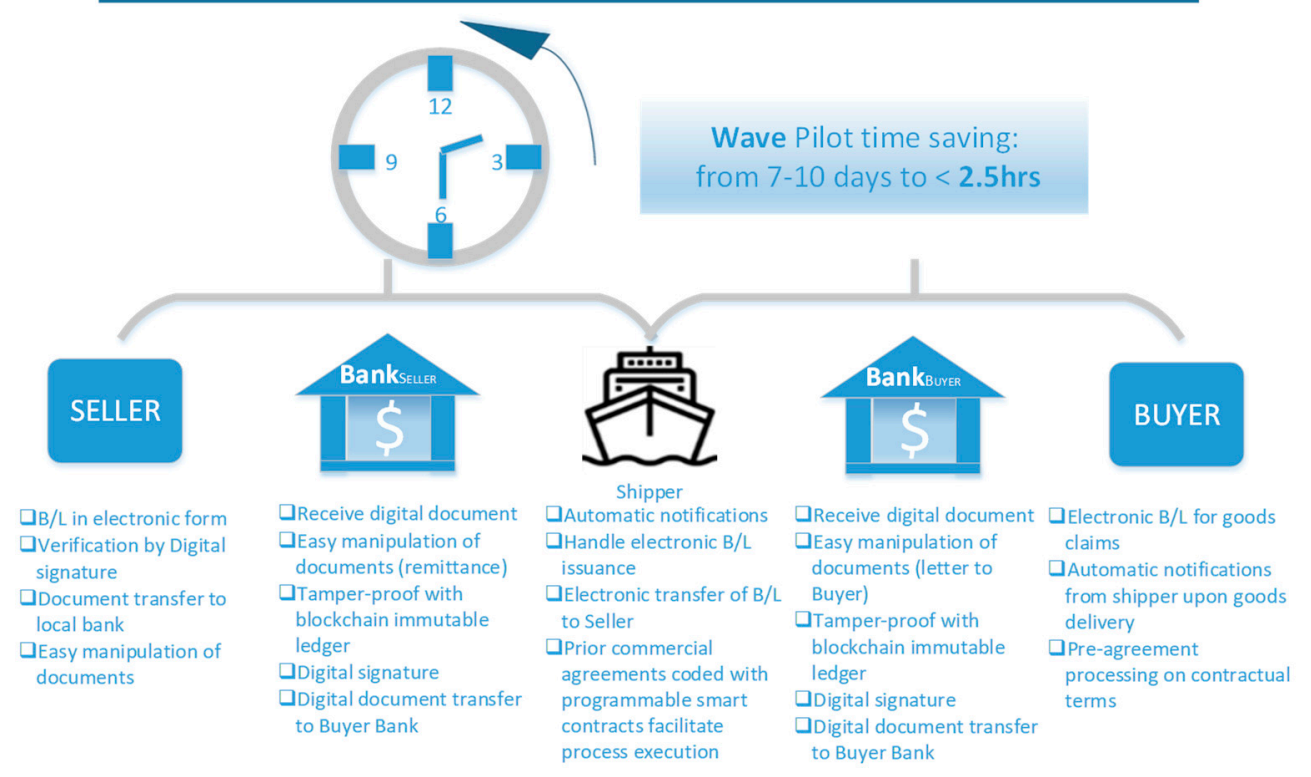

Figure 4. BBVA pilot program for improving international trade.

This digitization technique may apply to $\mathrm{B} / \mathrm{Ls}$ in $\mathrm{L} / \mathrm{C}$ payment processes. Moreover, smart contracts were programmed in accordance with contractual agreements that specified commercial terms and conditional statements of the $\mathrm{L} / \mathrm{C}$. Blockchain-based $\mathrm{L} / \mathrm{C}$ and $\mathrm{B} / \mathrm{L}$ systems also facilitate financing execution through the autonomous features of smart contracts. For shipping companies, this project also provided better provenance tracking and visibility for handovers of goods and documents.

\section{Results}

This section summarizes the characteristics of the selected cases and illustrates the rationale of the blockchain paradigm shift. We use the underlying rationale of each project to elaborate on the drive for an $\mathrm{L} / \mathrm{C}$ paradigm shift. Moreover, we examine the role of blockchain $\mathrm{L} / \mathrm{C}$ in achieving various objectives of trade finance. 


\subsection{Findings from Cases}

In general, trade finance is highly dependent on centralized operating mechanisms. Banks, as major trust providers, function as the processor of $\mathrm{L} / \mathrm{C}$ transactions. In a blockchain platform, banks still play the critical role of the dominator. Trade finance is conducted and audited via banks primarily for security and trust concerns. Among the various types of blockchain, a consortium chain is favored in the context of trade finance. Selected cases present a consortium blockchain as the best platform type to enhance the governance of financial transactions. In addition, trade finance using L/C deals with considerable manual processing and paperwork. Hence, all selected cases share the common need of devising a blockchain-based mechanism in order to process trade-related documents. In particular, the digitization of $\mathrm{L} / \mathrm{C}$ and $\mathrm{B} / \mathrm{L}$, to some extent, represents the need for logging key contract terms on the blockchain. In this sense, participating parties may check for or be notified regarding changes in status across trade processes.

Smart contracts allow the execution of contract terms or agreements as programmable enablers. Event-driven mechanisms formulate the interaction of smart contracts and allow business process automation, along with traceability notification. L/C payments may be conducted via preset transaction conditions while related parties confirm the validation and verification of transactions. For practical demands, smart contracts may invoke one another via functional calls as what is done in the context of computer programming language. Key parameters may be set on demand, such as trade-related numbers, dates, or shipment conditions. Smart contracts, in various cases, can help with administrative details and enhance the streamlined execution or transmission of trade information.

It is noted that blockchain-based platforms improve dependability and accountability for trade actors. For example, the cases of Ornua and Mizuho/Marubeni indicated that trade participants were forced to follow the rules presented in trade documents and be held responsible for their actions. The transaction logs generated by participant interactions are recorded to the shared ledger according to critical contractual terms. Transactional data that are checked and verified by the collaborative network avert attempts at tampering. The blockchain can also help in the transfer and identification of digital assets, which facilitates trade finance processing during numerous handovers. Digitized assets may be validated for authenticity by encrypted keys and measures such as digital signatures. From the cases of Maersk/IBM and HSBC/Cargill, blockchain potential is found in the cost reduction of exchange of trade documentation. This capability demonstrates the immutable and auditable attributes that the blockchain mechanism provides in trade financing activities. Efforts on processing paper-based procedures are reduced through the shared transaction ledger and thereby improve the timeliness and efficiency of trade workflows. In addition, the case of Maersk/IBM illustrates the potential of blockchain technology incorporation. The blockchain can serve as a distributed database that serves to address major security requirements of the IoT to improve device manipulation and data management [50]. In the case of BBVA, smart contracts automatically enabled the execution of contract terms that were followed by business logic.

\subsection{Driving Factors of the Paradigm Shift}

Blockchain L/C cases illustrate the potential of the L/C paradigm shift. In general, the blockchain L/C application may streamline trade-related activities and annoying handovers that frequently happened in traditional L/C finance. Particularly, the reduction of paper-based processing may help participants collaboratively build up network relationships to attain a more sustainable business environment [3]. However, critical impact factors such as system transparency, traceability, cost reduction, and user experience are possible areas for further investigation. Researchers have devoted effort to the exploration of blockchain adoption behaviors in the logistics and supply chain fields, in terms of technology adoption and network theories [7]. The most important drivers for blockchain adoption reported by researchers are cost reduction, the establishment of trust-free mechanisms, increased efficiency, enhanced transparency, and accountability [28]. Moreover, it is obvious that the blockchain has technical limitations at the current stage. Typical issues such as block size, 
transaction throughput, privacy concerns, and scalability are adversely affecting corporate willingness for business investment. To better leverage the effect of blockchain technology, multiple participation parties, including customs agents and governmental units, may be necessary to facilitate an overall network effect.

In addition, the digitization level of traditional documents may influence the effectiveness of using a blockchain solution. Challenges, such as scalability, platform standard, legal effect, distributed governance, and social impact, have a crucial influence on the future adoption and development of blockchain-based trade finance.

\section{Discussion}

\subsection{Impact of Blockchain L/C Adoption and Research Implications}

Table 2 summarizes the potential influence of blockchain $\mathrm{L} / \mathrm{C}$ on improving trade finance. We consider five major dimensions related to the adoption of blockchain $\mathrm{L} / \mathrm{C}$ processes and illustrate their connection to various cases.

Table 2. Impact dimension of the use of blockchain in trade finance and L/C payment.

\begin{tabular}{|c|c|c|}
\hline Impact Dimension & Blockchain's Role & $\begin{array}{c}\text { Mechanism or Applied Scenario } \\
\text { [Selected Case] }\end{array}$ \\
\hline \multirow{5}{*}{ Transparency } & $\begin{array}{l}\text { Supporting auditable records of transactions by its } \\
\text { distributed shared ledger }\end{array}$ & Shared transaction records [A-E] \\
\hline & $\begin{array}{l}\text { Collaboratively verifying critical transactions or property } \\
\text { transfer by its participating nodes using its shared database }\end{array}$ & Consensus mechanism [A-E] \\
\hline & $\begin{array}{l}\text { Physical property digitization and establishment of } \\
\text { immutable transactions on the common shared ledger }\end{array}$ & $\begin{array}{l}\text { Identity hashing with } \\
\text { assets/documents [A-E] }\end{array}$ \\
\hline & $\begin{array}{l}\text { Reducing fraud and counterfeit of goods/document across } \\
\text { transaction journey }\end{array}$ & $\begin{array}{l}\text { Digital signature and validation } \\
\text { [A-E] }\end{array}$ \\
\hline & Providing participants with access to transaction records & $\begin{array}{c}\text { Looking up records via transaction } \\
\text { nodes }[\mathrm{A}-\mathrm{E}]\end{array}$ \\
\hline \multirow[t]{2}{*}{ Information transmission } & $\begin{array}{l}\text { Enabling broadcast of verified and } \\
\text { time-stamped transactions }\end{array}$ & Consensus mechanism [A-E] \\
\hline & Automatic execution of Blockchain's trade activities & Event-driven mechanism [A-E] \\
\hline \multirow[t]{2}{*}{ Traceability } & Visualization of physical flow of goods/documents. & $\begin{array}{l}\text { Monitoring the change of state on } \\
\text { logistics/documental flow [A-E] }\end{array}$ \\
\hline & Near real-time notifications & Event-driven mechanism [A-E] \\
\hline Dis-intermediation & Cash settlement and validity check of trade documents & $\begin{array}{l}\text { Hashing digital signature of a } \\
\text { digital trade document }[A-E]\end{array}$ \\
\hline \multirow{2}{*}{ Cost } & Streamlining administrative processes & $\begin{array}{l}\text { Reducing the presentation of } \\
\text { paper-based documents [A-E] }\end{array}$ \\
\hline & $\begin{array}{l}\text { Shortening the duration of waiting and lowering down } \\
\text { transaction fees }\end{array}$ & $\begin{array}{l}\text { Removal or mitigation of manual } \\
\text { processing [A-E] }\end{array}$ \\
\hline Incorporation of IoT & Facilitating storage of tracking records & Distributed database $[\mathrm{C}]$ \\
\hline
\end{tabular}

The blockchain provides improvements in various aspects of trade finance. In this study, we focused on six major dimensions of the blockchain, namely, transparency, information transmission, traceability, disintermediation, cost, and the incorporation of IoT for the analysis of the impact of blockchain-based trade finance, particularly in supporting an $\mathrm{L} / \mathrm{C}$ payment process.

\subsubsection{Transparency}

In a blockchain-based trading system, transaction records are immutably replicated and kept by participating nodes. Broadcast by the participating nodes on the blockchain, transaction records may be checked, and blockchain data can be pervasively accessed to enhance transparency and auditability. This obviates, or at least alleviates, the need for certified trusted parties and a consensus mechanism, which reduces the opportunity for fraud and malicious activity. In addition, the combination of digitized property/assets and the blockchain system enables users to independently validate identity 
and creates a traceable audit for authenticity [51]. Thus, the transfer of ownership and the validation of identity are more transparent and auditable during transactions. Participating parties, therefore, benefit from a reduction in the cost of such confirmation.

\subsubsection{Information Transmission}

In these cases, the blockchain enables trading parties (carriers, exporters, importers, and banks) to share common distributed ledgers for trade finance. Through the use of smart contracts, trade documents may be digitized to facilitate the automatic execution of trade processes via preset codes. Moreover, event-driven mechanisms facilitate the flow of critical information among parties. In this sense, trade friction and painful handovers of goods/documents could be greatly reduced to reach near real-time response of workflow status. For example, IBM and Maersk leveraged a blockchain L/C to reduce document transmission time from days to less than a few hours. Repeated confirmation or manual checks, needed in typical trade logistics/payment contexts, may be eliminated from trade processes by introducing smart contract event mechanisms and using related IoT technology.

\subsubsection{Traceability}

Logistics traceability has been subjected to shipment handovers, thus hindering the pursuit of better trade performance. Traders often wait for a notification to activate certain business activities, for example, making payment upon the arrival of goods or presentation of documents. Smart contracts deployed on the blockchain provide a parallel function by enabling the automatic notification of status changes [52]. Similar concepts also apply to the tracking of trade documents. The blockchain allows trade document digitization and the attachment of such documents through the use of cryptographic algorithms that help in the realization of integrity and the prevention of counterfeiting.

\subsubsection{Disintermediation}

In trade finance, many traditional intermediaries hinder the speed of transactions. The blockchain facilitates the processing of cash settlements and saves companies time and money. In addition, combined with the unique features of the blockchain, a validity check of trade documents may be conducted without the need for certified and trusted third parties. This refers to the fact that diverse trading parties could be connected to a single transactional network without intermediaries providing trust. Thus, trade workflows could also be expedited and better performance achieved through the use of blockchain-related technologies.

\subsubsection{Cost}

Cost is one of the major concerns of promoting L/C finance processes. Companies have spent considerable amounts on minimizing trade-related administrative details in cross-border transactions. Handovers across shipping routes have lowered the efficiency of process flow and made business less competitive under other payment options, such as inter-firm trade credit [12]. The blockchain may streamline trade processes and demand less when compared with traditional payment systems. The main reason is the reduction in the cost of centralized service providers. The elimination of documentation accounts for significant savings in the context of global trade. The blockchain, with its immutable shared ledger, ensures significant cost reductions. Manual paper-based procedures are also greatly reduced, and the time and workforce needed for document processing are eliminated. Maersk's case provided practitioners with confidence in terms of the manner in which digitized assets and documents are transferred across borders. From the perspective of transaction cost economics, blockchain applications also leverage their power on reducing related costs such as those related to searching, bargaining, and policing. 


\subsubsection{Incorporation of IoT}

Researchers have asserted the practical importance of emerging IoT in blockchain applications. The trade journey involves a great deal of information on logistics status, such as the location of goods, ownership of assets, etc. IoT enables the communication of properties. However, the lack of trust hinders information sharing among assets and devices of different parties. The blockchain, as an immutable ledger, could fill the gap of trust issues and facilitate the operation of the IoT, such as applications for machine-to-machine transactions, management of progress, and source tracking. Prior research devoted effort to functions, such as tracking provenance and logistics states, shipping environments, and the incorporation of the blockchain and IoT [50]. These trials are of value and may enrich the whole IoT ecosystem with the improved security and interoperability they bring in their wake. Trade participants also benefit from the enhancement of accurate tracking with the integration of these two technologies.

\subsection{Potential to Transform Trade Finance Practices}

Trade finance has placed growing interest in blockchain use cases. A number of pilot projects are looking forward to benefiting from the distributed ledger network. The blockchain may provide radical opportunities for supply chain transformation by virtue of its immutable, tamper-proof features. Among various applications, the blockchain, and its affiliated smart contract technology, offers better transparency, traceability, and process automation. Various parties in the international trade ecosystem conduct business activities under conditions of uncertainty and lack of trust in counterparties. A blockchain-based platform extends its performance by enlarging network effects, i.e., the more the participants the greater the collaborative effect. Network effects are essential for considering the pursuit of blockchain-based solutions.

From the foregoing discussion on these case studies, a potential paradigm shift in blockchain $\mathrm{L} / \mathrm{C}$ is expected to occur through a complete integration of blockchain $\mathrm{B} / \mathrm{L}$, invoicing procedure, and the IoT. The integration of related blockchain applications may enable the formulation of complete collaboration among trade parties. It is also suggested that such efforts be devoted to the reduction of paperwork processing in order to improve overall trade finance performance. In addition, the adoption of blockchain L/Cs may also facilitate distributed governance and process automation in global trade finance.

Managerially, the similarities of all cases illustrate the power of the distributed shared ledger, which aims to transform the way in which businesses conduct payment and asset transmission. In addition, the collaborative network plays a key role. The trade ecosystem may upgrade to a more efficient level as the multiple participant context is preferred for the operation of the blockchain network.

\section{Conclusions}

This paper explored the feasibility of blockchain technology in trade finance and the manner in which it may achieve the pursuit of trade finance facilitation from the perspective of $\mathrm{L} / \mathrm{C}$. Multi-case studies of L/C pilot projects are provided as early evidence that international trade and financial institutions have been dedicating effort to related fields. We illuminated the rationale propelling corporate adoption from selected cases and elaborated on the comparative advantages of blockchain-based L/C processes. The blockchain has the potential to reform business operations through its immutability, transparency, and interoperability. We may expect its capability to reduce paper-based manipulation, to improve trust among trade stakeholders, and to ensure the development of sustainable business environments as well as sustainable finance. The innovative working paradigm of trade finance may disrupt financing practices by eliminating the friction caused by information transmission/confirmation in the achievement of business-related environmental sustainability.

This work focused on the blockchain L/C pilot projects at an early stage, while more applications in trade finance need to be explored to extend the effort of the ecosystem. Blockchain technology 
may have innovative potential in process simplification or disintermediation. However, technical limitations [53] and legal concerns [54] could hinder its further adoption in practice. Typical challenges include scalability, throughput, and technical standards. In addition, case studies on potential pilot studies may bring positive, promising opportunities even as collaborative adoption from trade finance stakeholders may further leverage the potential of the blockchain.

This study briefly illustrated common characteristics of selected cases, whereas the evaluation of individual case performance was left for future investigations. More academic or quantitative efforts exploring the fundamentals of blockchain adoption may provide a more comprehensive perspective. Future research should emphasize security concerns, as well as the incorporation of IoTs, to supplement the need for process automation along with the pursuit of transparency and accountability. In conclusion, it is suggested that research efforts be devoted to subjects related to customs and port administration, as the full paradigm shift may be achieved through collaborative networking among multiple international trade stakeholders.

Author Contributions: While all authors contributed about equally to the research presented in this paper and to the preparation of the manuscripts, the first author (S.E.C.) arranged for the project resources and acted as the principal investigator of the overall project, and the third author (Y.C.) coordinated all paper submission and revision efforts. All authors have read and agreed to the published version of the manuscript.

Funding: This research was supported by the Ministry of Science and Technology, Taiwan, under contract number MOST-106-2221-E-005-053-MY3.

Conflicts of Interest: The authors declare no conflict of interest.

\section{References}

1. Casino, F.; Dasaklis, T.K.; Patsakis, C. A systematic literature review of blockchain-based applications: Current status, classification and open issues. Telemat. Inform. 2019, 36, 55-81. [CrossRef]

2. Kracher, B.; Corritore, C.L.; Wiedenbeck, S. A foundation for understanding online trust in electronic commerce. J. Inf. Commun. Ethics Soc. 2005, 3, 131-141. [CrossRef]

3. Popescu, C.R.G.; Popescu, G.N. An exploratory study based on a questionnaire concerning green and sustainable finance, corporate social responsibility, and performance: Evidence from the Romanian business environment. J. Risk Financ. Manag. 2019, 12, 162. [CrossRef]

4. Popescu, C.R.G.; Popescu, G.N. Risks of cyber attacks on financial audit activity. Audit. Financ. 2018, 16, 54-147. [CrossRef] [PubMed]

5. Jessel, B.; DiCaprio, A. Can blockchain make trade finance more inclusive? J. Financ. Transform. 2018, 47, $35-50$.

6. Kshetri, N. 1 Blockchain's roles in meeting key supply chain management objectives. Int. J. Inf. Manag. 2018, 39, 80-89. [CrossRef]

7. Queiroz, M.M.; Telles, R.; Bonilla, S.H. Blockchain and supply chain management integration: A systematic review of the literature. Supply Chain Manag. 2019. [CrossRef]

8. Chang, S.E.; Chen, Y.C.; Lu, M.F. Supply chain re-engineering using blockchain technology: A case of smart contract based tracking process. Technol. Forecast. Soc. Chang. 2019, 144,1-11. [CrossRef]

9. Smart Contracts: Building Blocks for Digital Markets. Available online: http://www.fon.hum.uva.nl/ rob/Courses/InformationInSpeech/CDROM/Literature/LOTwinterschool2006/szabo.best.vwh.net/smart_ contracts_2.html (accessed on 19 October 2018).

10. Chang, S.E.; Chen, Y.C.; Wu, T.C. Exploring blockchain technology in international trade. Ind. Manag. Data Syst. 2019, 119, 1712-1733. [CrossRef]

11. Kant, R. Is letter of credit losing ground in international trade? Vinimaya 2016, 37, 42.

12. Clark, J. Trade finance: Developments and issues. CGFS Pap. 2014, 50.

13. Bitcoin: A Peer-to-Peer Electronic Cash System. Available online: http://www.bitcoin.org/bitcoin.pdf/ (accessed on 19 October 2018).

14. Wang, Y.; Han, J.H.; Beynon-Davies, P. Understanding blockchain technology for future supply chains: A systematic literature review and research agenda. Supply Chain Manag. 2019, 24, 62-84. [CrossRef] 
15. Kim, J.S.; Shin, N. The impact of blockchain technology application on supply chain partnership and performance. Sustainability 2019, 11, 6181. [CrossRef]

16. Gatteschi, V.; Lamberti, F.; Demartini, C.; Pranteda, C.; Santamaría, V. To blockchain or not to blockchain: That is the question. IT Prof. 2018, 20,62-74. [CrossRef]

17. Tapscott, D.; Tapscott, A. Blockchain Revolution: How the Technology Behind Bitcoin Is Changing Money, Business, and the World; Portfolio: London, UK, 2016.

18. Fernandez-Vazquez, S.; Rosillo, R.; De La Fuente, D.; Priore, P. Blockchain in FinTech: A mapping study. Sustainability 2019, 11, 6366. [CrossRef]

19. Guo, Y.; Liang, C. Blockchain application and outlook in the banking industry. Financ. Innov. 2016, 2, 1-12. [CrossRef]

20. Tijan, E.; Aksentijevi'c, S.; Ivani'c, K.; Jardas, M. Blockchain technology implementation in logistics. Sustainability 2019, 11, 1185. [CrossRef]

21. Three Common Misconceptions about Smart Contracts. Available online: https://bitsonblocks.net/2017/03/ 07/three-common-misconceptions-about-smart-contracts/ (accessed on 19 October 2018).

22. Kuhn, T. The Structure of Scientific Revolutions, 2nd ed.; University of Chicago Press: Chicago, IL, USA, 1970.

23. Gutting, G. Paradigms and Revolutions: Applications and Appraisals of Thomas Kuhn's Philosophy of Science; University of Notre Dame Press: South Bend, IN, USA, 1980.

24. Viriyasitavat, W.; Hoonsopon, D. Blockchain characteristics and consensus in modern business processes. J. Ind. Inf. Integr. 2019, 13, 32-39. [CrossRef]

25. Eisenhardt, K.M.; Graebner, M.E. Theory building from cases: Opportunities and challenges. Acad. Manag. J. 2007, 50, 25-32. [CrossRef]

26. Rowley, J. Using case studies in research. Manag. Res. News 2002, 25, 16-27. [CrossRef]

27. Yin, R.K. Case Study Research and Applications: Design and Methods; Sage: Thousand Oaks, CA, USA, 2017.

28. Gausdal, A.H.; Czachorowski, K.V.; Solesvik, M.Z. Applying blockchain technology: Evidence from Norwegian companies. Sustainability 2018, 10, 1985. [CrossRef]

29. Thomas, G. A typology for the case study in social science following a review of definition, discourse, and structure. Qual. Inq. 2011, 17, 511-521. [CrossRef]

30. Baxter, P.; Jack, S. Qualitative case study methodology: Study design and implementation for novice researchers. Qual. Rep. 2008, 13, 544-559.

31. Creswell, J.W. Qualitative Inquiry and Research Design: Choosing among Five Approaches, 3rd ed.; Sage: Thousand Oaks, CA, USA, 2013.

32. Gerring, J. What is a case study and what is it good for? Am. Political Sci. Rev. 2004, 98, 341-354. [CrossRef]

33. Seawright, J.; Gerring, J. Case-selection techniques in case study research: A menu of qualitative and quantitative options. Political Res. Q. 2008, 61, 294-308. [CrossRef]

34. Daimler and LBBW Successfully Utilize Blockchain Technology for Llaunch of Corporate Schuldschein. Available online: http://media.daimler.com/marsMediaSite/en/instance/ko/Daimler-and-LBBW-successfullyutilize-blockchain-technology-for-launch-of-corporate-Schuldschein.xhtml?oid=22744703 (accessed on 1 February 2019).

35. Blockchain Sharpens Dianrong's Edge in P2P Lending to Small Businesses. Available online: www.scmp.com/ tech/leaders-founders/article/2102840/blockchain-sharpensdianrongs-edge-p2p-lending-small (accessed on 1 February 2019).

36. CGI and Its Bank Partners Achieve Ground-Breaking Interoperability between CGI Trade360 and Skuchain's Blockchain Platform. Available online: http://markets.businessinsider.com/news/stocks/cgi-and-its-bankpartnersachieve-ground-breaking-interoperability-between-cgitrade360-and-skuchain-s-blockchainplatform-1004482577 (accessed on 1 February 2019).

37. What Is Origintrail? Available online: https://origintrail.io (accessed on 1 February 2019).

38. Stvilia, B.; Gasser, L.; Twidale, M.B.; Smith, L.C. A framework for information quality assessment. J. Am. Soc. Inf. Sci. Technol. 2007, 58, 1720-1733. [CrossRef]

39. Eppler, M.J. Managing Information Quality: Increasing the Value of Information in Knowledge-Intensive Products and Processes; Springer: Berlin, Germany, 2006.

40. Blockchain Revolution in Trade Finance. Available online: https:/www.barclayscorporate.com/insights/ innovation/blockchain-revolution-in-trade-finance/ (accessed on 1 February 2019). 
41. Ornua Completes World First Blockchain Trade through Collaboration with Barclays. Available online: https://ornua.ebowdev.com/ornua-completes-world-first-blockchain-trade-through-collaborationwith-barclays/ (accessed on 1 February 2019).

42. Trade Finance and Blockchain-Three Essential Case Studies. Available online: http://cib.db.com/ insights-and-initiatives/flow/trade_finance_and_the_blockchain_three_essential_case_studies.htm (accessed on 1 February 2019).

43. Mizuho Completes Trade Transaction Using Blockchain. Available online: https://www.gtreview.com/news/ asia/mizuho-completes-trade-transaction-using-blockchain/ (accessed on 1 February 2019).

44. Conclusion of Trade Transaction Using Blockchain and Distributed Ledger Technology-Collaborative Effort with General Trading and Insurance Companies. Available online: https:/www.marubeni.com/en/news/ 2017/release/201707072.pdf (accessed on 1 February 2019).

45. Enable Business Processes to React to Blockchain Events. Available online: https://developer.ibm.com/ tutorials/cl-enable-bpm-business-processes-to-react-to-blockchain-events/ (accessed on 7 March 2018).

46. How IBM and Maersk Will Use the Blockchain to Change the Shipping Industry. Available online: http://www.nasdaq.com/article/how-ibm-and-maersk-willuse-the-blockchain-to-change-theshipping-industry-cm756797 (accessed on 1 February 2019).

47. Maersk Created a Solution for Letter of Credit Complication. Available online: https://www. morethanshipping.com/maersk-created-solution-letter-credit-complications/ (accessed on 1 February 2019).

48. Introducing R3 Corda: A Distributed Ledger Designed for Financial Services. Available online: https: //gendal.me/2016/04/05/introducing-r3-corda-a-distributed-ledger-designed-for-financial-services/ (accessed on 19 October 2018).

49. BBVA and Wave Carry Out the First Blockchain-Based International Trade Transaction between Europe and Latin America. Available online: https://www.bbva.com/en/bbva-and-wave-carry-first-blockchain-basedinternational-trade-transaction-europe-and-latin-america/ (accessed on 1 February 2019).

50. Panarello, A.; Tapas, N.; Merlino, G.; Longo, F.; Puliafito, A. Blockchain and IoT integration: A systematic survey. Sensors 2018, 18, 2575. [CrossRef]

51. Mainelli, M. Blockchain will help us prove our identities in a digital world. Harv. Bus. Rev. Digit. Artic. 2017, 2-6.

52. Wu, H.; Li, Z.; King, B.; Ben Miled, Z.; Wassick, J.; Tazelaar, J. A distributed ledger for supply chain physical distribution visibility. Information 2017, 8, 137. [CrossRef]

53. Bae, J. Blockchain as a myth of the decentralized processing system. Rev. Fair Econ. 2018, 3, 1-13.

54. Kim, J.-K. Cryptocurrency as a monetary or a financial asset. Rev. Fair Econ. 2018, 3, 1-21. 